Journal of Social Sciences 7 (3): 369-374, 2011

ISSN 1549-3652

(C) 2011 Science Publications

\title{
Achievement Motivation and Adjustment Patterns among International and National Players of Different Team Sports
}

\author{
${ }^{1}$ Nirmaljit Kaur Rathee and ${ }^{2}$ Jagbir Singh \\ ${ }^{1}$ Department of Physical Education, Faculty of Education, \\ Delaware State University, Dover, Delaware, USA \\ ${ }^{2}$ Physical Education Department, Department of Evening Studies, \\ Panjab University, Chandigarh, India
}

\begin{abstract}
Problem Statement: Achievement in sports demands specific behavior from an athlete.. The performer in such events must have ability to assess the situation, select the response, decide quickly and then implement it with determined efforts. Approach: This study was focused to examine the levels of achievement motivation, emotional and social adjustment among international and national players of basketball, hockey and handball games. Subjects $(\mathrm{N}=$ 240) were administered Achievement Motivation Test and Adjustment Inventory Analysis of variance $(2 \times 2$ factorial design) was applied to find out the significance of differences and interaction of gender and performance. Descriptive values were worked to find out the direction of differences and t-test was used to find out significance of inter sport differences. Results: International players had higher levels of achievement motivation $(\mathrm{M}=27.42, \mathrm{SD}=4.16)$ as compared to the National level players $(\mathrm{M}=24.84, \mathrm{SD}=3.98), \mathrm{F}=27.33(\mathrm{p}<0.01)$. No significant gender differences were notices on this construct. On emotional adjustment, the international players were emotionally better adjusted as compared to the national level players $(\mathrm{M}=12.25$ and 13.46 respectively, $\mathrm{F}=8.39, \mathrm{p}<0.01$ : low scores indicated better level of adjustment). International players were better adjusted socially $(M=7.19)$ than national players $(\mathrm{M}=7.80), \mathrm{F}=6.30, \mathrm{p}<0.01$. Male players were better adjusted both emotionally and socially as compared to female players. Male basketball and hockey players were emotionally and socially better adjusted than handball players. Among female players, handball group was better than basketball group on achievement motivation; basketball and handball groups were better than hockey group on emotional adjustment; whereas on social adjustment, basketball group was better than hockey group. Conclusions: The results provide evidence that high achievement motivation is a vital factor that distinguishes high level performers. Emotional stability and social adjustment were also the critical factors that differentiated between high and low level performers. Implications of the results regarding inter sports differences are also discussed.
\end{abstract}

Key words: Achievement motivation, social adjustment, emotional adjustment, high level performers

\section{INTRODUCTION}

Sports teams constitute a unique kind of group. Unlike some other collection of people to solve problems, teams have clear-cut goals and well defined roles for both coaches and players to adhere to. These teams participate in institutionalized competitive activities that involve rigorous physical exertion or the use of relatively complex physical skills by participants motivated by internal or external rewards. How motivated the players are, depends on the direction of their efforts i.e. what they seek out, what approach they adopt and what attracts them in a certain situation. When these efforts are exerted in right intensity, optimum output in performance is achieved (Weinberg and Gould, 2011). If two players have similar abilities, the deciding factor to indicate their achievement at higher levels may be the presence of a combination of

Corresponding Author: Dr. N.K. Rathee, Faculty of Education, Department of Physical Education, Delaware State University, Dover, Delaware, USA, 19711 


\section{J. Social Sci., 7 (3): 369-374, 2011}

desirable personality traits attuned with their desire to achieve. This desire or the motivation has attracted the attention of researchers for the last many decades. Motivation is at the heart of many of sport's most interesting problems, both as a developmental outcome of social environments such as competition and coaches' behaviors and as a developmental influence on behavioral variables such as persistence, perceptions of an ego-involving climate, learning, performance and achievement goals (Ormrod, 2011). To work best in any motivational state, it is important to know what motivates an athlete towards a particular achievement goal; the trait centered orientation, situation centered orientation or interactional orientation? (Weinberg and Gould, 2011). Thus, exploring the phenomena of motivation, its main elements may include: Motivation towards winning, motivation for individual excellence, motivation toward team goals and motivation towards achievement goals.

Achievement motivation cannot be described as something that occurs during competition but mostly as a trait having 'permanent character,' being formed during the preceding weeks, months and years. It is an essential element of human personality and it directs a person's activity and makes it more (or less) dynamic. This property, the "driving power of activity", should be understood as the joint function of the motive power (which is a permanent property of personality) and the consequences of what a given individual expects of his own actions (Franken, 1993). This action is a product of two tendencies: (1) to achieve a success and (2) to avoid a failure. People with greater achievement motivation prefer tasks and situations where they can do their best. Such people continue long lasting insoluble tasks more effectively and reveal greater persistence (Atkinson and Feather, 1966). Achievement motivation leads people to set realistic but challenging goals. High-achievers have a great desire to succeed and are not put off by the fear of failure. High-achievers tend to enjoy challenges (opponents who are equal to them or slightly superior to them); they need feedback and respond well to constructive criticism; and they do not fear failure, which means they persist at sports. To become an elite athlete in any sport requires hours upon hours of training. Often this training is rigorous, painful, or injurious. However, the athletes who have reached the pinnacle of their sport have more than likely put in their time to get to achieve that high level of success. To do this, these athletes must have something that motivates them to continually push their bodies and come back from whatever struggles or setbacks they may experience along the way (Kamlesh, 2004). On the other hand, achievement motivation often causes disappointment of those players who are not predestined to participate at high level performance by the basics of their personality. These players who do not possess high level of achievement motivation do not reach the highest levels of their game despite good results at a young age. In a match situation they usually tend to evoke excessive stimulation which affects the quality of their sports performance adversely. In the long term this often leads to a lack of progress or even giving up practicing. Perhaps, leadership developmental based orientations on emotional and social competencies and group strategies may be adopted instead of traditional approaches in training and coaching for such players (Cherniss et al., 2010). Research indicate that achievement motivation can facilitate the development of a self-determined, more task-involving climate and the ensuing support of perceived competence in sport settings, may encourage positive affective states and reduce negative affective states among individual performers (Quested and Duda, 2009; Reinboth and Duda, 2006). Goal orientation perspective may represent a dispositional tendency towards judging one's competence or it may be fostered within the situational context creating a perceived motivational climate.

Differences among different sport groups on motivation suggest the need to further examine factors of motivation with a broader representation of individual and team sport athletes (Schilling and Hayashi, 2001). Research has shown that sport participation is not only affected by emotional and social adjustment patterns, but it also tends to encourage positive social skills (Donaldson and Ronan, 2006). This tends to increase behavioral adaptations, optimize emotions and help athletes tackle competitive pressure (Pensgaard and Duda, 2003). Social factors do influence the acquisition of high levels of sport proficiency and it is vitally important to acknowledge that environmental constraints on expertise can be broad (e.g., cultural factors) and/or narrow (e.g., family or coaching factors) (Baker et al., 2003). Researchers have been trying to identifying the factors that distinguish exceptional players from the ordinary performers and there have been numerous attempts to find out the traits and qualities that distinguish a champion from other players, but our understanding is still far from complete. Given this background it was deemed appropriate to conduct this research to explore the levels of achievement motivation along with emotional and social adjustment patterns among players of different team sports performing at different levels.

\section{MATERIALS AND METHODS}




\section{J. Social Sci., 7 (3): 369-374, 2011}

In order to investigate the levels of achievement motivation, emotional and social adjustment among Indian players of three selected sports groups i.e. basketball, hockey and handball, the players $(\mathrm{N}=240$, age group 17-25) were selected as subjects. Half of these subjects had participated in their respective sport at National level and others were those who had participated at International level. Endeavors were also made to have equal number of subjects from the two genders. To find out the level of achievement motivation among the subjects, Achievement Motivation Test was administered. The test retest reliability of this scale with $\mathrm{N}=70$ was reported to be 0.70 and its validity against another measure of achievement was also 0.70 . This scale consisted of 20 statements with two options as answers, the correct answers were awarded 2 points and the incorrect ones were awarded zero. Sum total score reflected the achievement motivation level of the individual taking the test. According to the instructions provided in the Test manual, high scores indicated higher level of achievement motivation. To obtain data with regard to the emotional and social adjustment levels among the subjects, the Adjustment Inventory (Sinha and Singh, 1980) was utilized. For this Inventory, the reliability coefficient using split half method was reported to be 0.95 and 0.97 respectively for emotional and social adjustments. Correct answers were given 1 score and incorrect response was given 0. Low scores indicated better adjustment levels among the subjects. Analysis of variance $(2 \times 2$ factorial design) was applied to find out the significance of differences and the interaction of gender and performance. Descriptive values were worked out to find the direction of differences and ttest was used to find out the significance of inter sport differences. For the purpose of this research the level of significance was set at 0.05 .

\section{RESULTS}

To find out the differences among the two performance level groups (i.e., International and National) and the two gender groups on Achievement Motivation, $2 \times 2$ analysis of variance was applied and descriptive values (mean and SD) were worked out. These results have been presented in Tables 1 and 2 respectively.

From a perusal of the results in Table 1 it can be observed that the differences between the two performance levels i.e. national and international have been found to be significant at 0.01 level ( $\mathrm{F}$ value being 27.33).
Table 1: Results with regard to the two performance groups and the two gender groups on achievement motivation

\begin{tabular}{lrrrc}
\hline Source of variance & \multicolumn{1}{c}{ Ss } & \multicolumn{1}{c}{ df } & \multicolumn{1}{c}{ Ms } & F-Value \\
\hline 2 Performance groups & 533.02 & 1 & 533.02 & $27.33^{* *}$ \\
2 gender groups & 4.74 & 1 & 4.74 & 0.24 \\
Performance x gender & 19.51 & 1 & 19.51 & 1.00 \\
Within & 6162.00 & 236 & 26.11 & \\
\hline
\end{tabular}

**: $\mathrm{p}<0.01$

Table 2: Mean and SD values on achievement motivation

\begin{tabular}{|c|c|c|c|c|}
\hline \multirow[b]{2}{*}{ Descriptive } & \multicolumn{2}{|c|}{ Performance category } & \multicolumn{2}{|c|}{ Gender } \\
\hline & National & International & Male & Female \\
\hline Mean & 24.84 & 27.42 & 26.01 & 26.26 \\
\hline SD & 3.98 & 4.16 & 4.60 & 4.49 \\
\hline
\end{tabular}

Table 3: Results with regard to the two performance groups and the two gender groups on emotional adjustment

\begin{tabular}{lrrrr}
\hline Source of variance & \multicolumn{1}{l}{ Ss } & \multicolumn{1}{l}{ df } & \multicolumn{1}{l}{ Ms } & F-Value \\
\hline 2 Performance groups & 116.40 & 1 & 116.40 & $8.39^{* *}$ \\
2 Gender groups & 416.33 & 1 & 416.33 & $30.00^{* *}$ \\
Performance x gender & 8.78 & 1 & 8.78 & 0.63 \\
Within & 4384.60 & 236 & 18.58 & \\
\hline
\end{tabular}

**: $\mathrm{p}<0.01$

Table 4: Mean and SD values on emotional adjustment

\begin{tabular}{lllll}
\hline & Performance category & Gender & \\
Descriptive & & & - & \\
Values & National & International & Male & Female \\
\hline Mean & 13.46 & 12.25 & 11.71 & 13.99 \\
SD & 4.03 & 3.74 & 3.60 & 3.92 \\
\hline
\end{tabular}

Referring to mean values of these two groups in Table 2 , it has been found that the International players were having higher levels of achievement motivation (mean score 27.42) as compared to the National level players (mean score 24.84).With regard to the levels of emotional adjustment among the subjects, the results of $2 \times 2$ ANOVA and the descriptive values have been presented in Tables 3 and 4 respectively. The results in Table 3 have demonstrated significant differences between the two performance level groups on emotional adjustment $(\mathrm{p}<0.01, \mathrm{~F}=8.39)$. The mean values in Table 4 have revealed that international players had obtained lower mean scores of 12.25 whereas national players had 13.46 mean score and thus were emotionally better adjusted as compared to the national level players (as per the instructions in the Adjustment Inventory, low scores indicated better emotional stability). The differences among the two gender groups have also been found to be significant $(\mathrm{F}=$ $30.00, \mathrm{p}<0.01)$ and male players have exhibited significantly higher levels of emotional stability as compared to their female counterparts.

The results with regard to social adjustment derived from analysis of variance and the descriptive values for the two performance level groups and the two gender groups have been depicted in Tables 5 and 6. 


\section{J. Social Sci., 7 (3): 369-374, 2011}

Table 5: Results with regard to the two performance groups and the two gender groups on Social Adjustment

\begin{tabular}{lrrrr}
\hline Source of Variance & \multicolumn{1}{c}{ Ss } & \multicolumn{1}{c}{ df } & \multicolumn{1}{l}{ Ms } & F-Value \\
\hline 2 Performance groups & 30.01 & 1 & 30.01 & $6.30^{* *}$ \\
2 Gender groups & 57.80 & 1 & 57.80 & $12.14^{* *}$ \\
Performance x gender & 4.05 & 1 & 4.05 & 0.85 \\
Within & 1504.00 & 236 & 6.37 & \\
\hline
\end{tabular}

**: $\mathrm{p}<0.01$

Table 6: Mean and SD values on social adjustment

\begin{tabular}{lllll}
\hline & Performance category & Gender & \\
Descriptive & - & & & \\
Values & National & International & Male & Female \\
\hline Mean & 7.80 & 7.19 & 7.07 & 7.92 \\
SD & 2.35 & 2.07 & 2.22 & 2.17 \\
\hline
\end{tabular}

Table 7: Mean, SD and t-values relating to male player of selected sports groups on achievement motivation, emotional and social adjustment

\begin{tabular}{|c|c|c|c|c|c|c|}
\hline \multirow{2}{*}{ Variable } & & \multirow[b]{2}{*}{ Group } & \multirow[b]{2}{*}{ Mean } & \multirow[b]{2}{*}{ SD } & \multicolumn{2}{|c|}{ t-ratio matrix } \\
\hline & & & & & 2 & 3 \\
\hline Achievement & 1 & Basketball & 26.55 & 4.71 & 0.92 & 0.32 \\
\hline \multirow[t]{2}{*}{ Motivation } & 2 & Hockey & 25.60 & 4.53 & & 0.55 \\
\hline & 3 & Handball & 25.20 & 5.18 & & - \\
\hline Emotional & 1 & Basketball & 11.07 & 2.71 & 0.48 & $2.43 *$ \\
\hline \multirow[t]{2}{*}{ Adjustment } & 2 & Hockey & 10.72 & 3.77 & & $2.54 *$ \\
\hline & 3 & Handball & 12.97 & 4.13 & & - \\
\hline Social & 1 & Basketball & 6.35 & 2.25 & 1.17 & 3.70 **: \\
\hline \multirow[t]{2}{*}{ Adjustment } & 2 & Hockey & 6.92 & 2.20 & & $2.62 *$ \\
\hline & 3 & Handball & 8.27 & 2.41 & & - \\
\hline
\end{tabular}

Table 8: Mean, SD and t-values relating to female player of selected sports groups on achievement motivation, emotional and social adjustment

\begin{tabular}{|c|c|c|c|c|c|c|}
\hline \multirow[b]{2}{*}{ Variable } & & \multirow[b]{2}{*}{ Group } & \multirow[b]{2}{*}{ Mean } & \multirow[b]{2}{*}{ SD } & \multicolumn{2}{|c|}{ t-ratio matrix } \\
\hline & & & & & 2 & 3 \\
\hline Achievement & 1 & Basketball & 24.35 & 4.55 & 1.33 & $2.89 * *$ \\
\hline \multirow[t]{2}{*}{ Motivation } & 2 & Hockey & 25.60 & 3.85 & & 1.74 \\
\hline & 3 & Handball & 27.12 & 3.99 & & - \\
\hline Emotional & 1 & Basketball & 13.30 & 4.43 & $4.08 * *$ & 0.02 \\
\hline \multirow[t]{2}{*}{ Adjustment } & 2 & Hockey & 16.60 & 2.50 & & $4.66^{* *}$ \\
\hline & 3 & Handball & 13.32 & 3.66 & & - \\
\hline Social & 1 & Basketball & 7.30 & 2.07 & $3.89 * *$ & 1.66 \\
\hline \multirow[t]{2}{*}{ Adjustment } & 2 & Hockey & 8.87 & 1.48 & & 1.97 \\
\hline & 3 & Handball & 8.07 & 2.09 & & - \\
\hline
\end{tabular}

The ANOVAs results projected in Table 5 on Social adjustment have revealed that the two performance groups differed from each other significantly $(\mathrm{p}<0.01, \mathrm{~F}$ $=6.30$ ). When these results are interpreted by utilizing the mean scores for these groups in Table 6, it appears that international players were significantly better adjusted socially as compared to the national players.
Similarly, significant gender differences have also been observed among the two gender groups $(\mathrm{p}<0.01, \mathrm{~F}=$ 12.14). The male players having obtained lower mean scores of 7.07 (as compared to 7.92 for female players) were found to be significantly better adjusted socially.

To find out the differences among male players of selected sports groups i.e. basketball, hockey and handball, mean scores, SD values and t-values were worked out and the results have been presented in Table 7.

The results depicted in Table 7 have revealed that so far as the levels of their achievement motivation were concerned, there were no significant differences among the male players of three selected sports groups and all the male subjects were found to have almost similar levels of achievement motivation. However, on emotional as well as social adjustment, male handball players had significantly lowers levels of adjustment, i.e., they were less adjusted emotionally and socially as compared to the other two performance groups.

The mean scores, SD values and t-values were worked out relating to female players of three selected sports groups and the results have been presented in Table 8.

From the results in Table 8 it can be observed that on achievement motivation, there were significant differences among basketball and handball groups. The female handball players had significantly higher levels of achievement motivation as compared to basketball players $(\mathrm{p}<0.01, \mathrm{t}=2.89)$. On both emotional adjustment as well as social adjustment the basketball players were significantly better adjusted than the hockey players ( $\mathrm{p}<0.01$ in both cases, $\mathrm{t}=4.08$ and 3.89 respectively). Even handball players have been found to be significantly better adjusted emotionally than the hockey players $(\mathrm{p}<0.01, \mathrm{t}=4.66)$.

\section{DISCUSSION}

It has been found that the international players were having higher levels of achievement motivation as compared to the national level players $(\mathrm{p}<0.01$, Table 1). These findings support Dureha et al. (2010) who had noticed significant differences on achievement motivation levels of hockey national and international players. It seems that high level of achievement motivation is one of the attributes of higher performance level groups that acted as a drive for them to strive towards excellence. The analysis indicates that achievement motivation can be identified as one property which determines the progress of young players with serious aspirations to play at international level. Regarding the two gender groups, they had almost 


\section{J. Social Sci., 7 (3): 369-374, 2011}

similar levels of achievement motivation. It seems that achievement motivation was not the mediating factor so far as the gender differences were concerned.

On emotional adjustment, international players were found to be emotionally better adjusted as compared to the national level players. Better emotional stability helps an athlete to remain focused on the task and enables him to put in his best efforts even when faced with tough situations. Pangma et al. (2009) have observed direct relationship between achievement motivation and adversity quotient. Emotional adjustability helps an athlete in successfully dealing with the pressures of stressful situations occurring in competitive sport. Regarding gender differences, male players have been found to be emotionally better adjusted as compared to their female counterparts ( $<<0.01$, Tables 3$)$. These gender differences might have been the result of prevailing social structure in the country and the social roles assigned to each gender with respect to their culture. In most part of the country, males play a dominant role in almost all spheres of life and females lead a somewhat sheltered life (Parveen and Iqbal, 2007).

With regard to social adjustment, international players have been found to be significantly better adjusted socially as compared to the national players $(\mathrm{p}<0.01$, Table 5). This may be due to the social exposure that the international players get, facilitating their social interaction with others, or it may be that their social competence helped them in outpacing others also noticed better social adjustment among higher level performance group. Regarding gender differences on social adjustment, male players were found to be socially better adjusted as compared to the female players $(\mathrm{p}<0.01$, Table 5$)$. The reason may be that in accordance with social and cultural set up in the country, male persons get more opportunities for social interaction than the females and this might have contributed to their better social adjustability. Social factors such as cultural influences and the relative age effect are also considered as determinants of sport expertise (Baker et al., 2003).

Regarding inter-sport differences, no significant differences were observed among the three sports groups on achievement motivation. However, on emotional adjustment, male handball players had significantly lowers levels of adjustment $(\mathrm{p}<0.05$ in both cases, Table 7), i.e., they were less adjusted emotionally as compared to the other two groups. On social adjustment, basketball group was better adjusted than the handball group ( $<<0.01)$ and hockey group was also better adjusted socially as compared to handball group ( $\mathrm{p}<0.05$, Table 7$)$.
So far as female players were concerned, handball players were having higher level of achievement motivation as compared to the basketball players $(\mathrm{p}<0.01)$. On adjustment, basketball and handball groups were found to be emotionally better adjusted than the hockey group ( $\mathrm{p}<0.01$ in both cases, Table 8 ). On social adjustment, basketball group has been found to be better adjusted socially than hockey group $(\mathrm{p}<0.01$, Table 8).

\section{CONCLUSION}

In the present study, the international players were found to have significantly higher levels of achievement motivation as compared to the national level players. It is perhaps this distinction that marks between high achievers and those who are not able to make to the higher level in competitive sports. These results provided evidence that high achievement motivation is an important factor that distinguishes high level performers (Butt and Cox, 1992). However, no significant gender differences were noticed on achievement motivation, which indicated that it was not gender specific.

With regard to emotional and social adjustment, international players were found to be significantly better than national level players. These findings point out that emotional stability and social adjustability were also the critical factors that differentiated between high and low level performers. There has been research that has linked physical activity and sports participation with improved mental and social well-being (Miller and Hoffman, 2009). Jones (2003) was also of the view that emotional and social factors could influence achievement motivation along with both physical and cognitive functioning which facilitates the acquisition of high levels of sport proficiency. In fact, these two factors serve an adaptational function that can mediate and energize subsequent behavior by ensuring that athletes channel extra physical and mental resources towards the specific task (Vallerand and Blanchard, 2000). Another significant finding of the present study (in line with those of Lawther, 1972) was that the male players were found to be better adjusted emotionally as well as socially as compared to female players. Though these findings draw support from Moreno-Murcia et al. (2011) who had reported gender differences on motivational disposition, perceived climate and self reported discipline, however, these differences might have occurred due to social and cultural environment to which the subjects of the present study belonged. Therefore, further investigations are required to substantiate such differences. 
Though some inter sport differences were noticed, both among male as well as female players, but no coherent and consistent pattern could be detected so as to render any finding for specific inter sport differences. However, in the present study, male handball players were found to have lower levels of emotional and social adjustment as compared to the other two sports groups. Among female players, handball players had higher levels of achievement motivation, whereas hockey players were found to have lower levels of emotional and social adjustment. Further research is needed to unfold existence of any sport specific peculiarities on the patterns of their emotional adaptability and social adjustability.

\section{REFERENCES}

Atkinson, J.W., 1966. An Introduction to Motivation. 1st Edn., Van Nostrand, New York, pp: 335.

Baker, J., S. Horton, J. Robertson-Wilson and M. Wall, 2003. Nurturing sport expertise: Factors influencing the development of elite athlete. J. Sports Sci. Med., 2: 1-9. http://www.jsportscimed.org/vol2/n1/1/v2n11pdf.pdf

Butt, D.S. and D.N. Cox, 1992. Motivational patterns in Davis Cup, university and recreational tennis players. Int. J. Sport Psychol., 23: 1-13. http://psycnet.apa.org/psycinfo/1993-15703-001

Cherniss, C., L.G. Grimm and J.P. Liautaud, 2010. Process-designed training: A new approach for helping leaders develop emotional and social competence. J. Manage. Dev., 29: 413-431. DOI: $10.1108 / 02621711011039196$

Coakley, J.J., 2009. Sports in Society. $1^{\text {st }}$ Edn., McGraw-Hill Education, London, ISBN: 0077117441, pp: 613.

Donaldson, S.J. and K.R. Ronan, 2006. The effects of sports participation on young adolescents' emotional well-being. Adolescence, 41: 369-389. PMID: 16981623

Dureha, D.K., M. Singh, S. Yaduvanshi and P. Mishra, 2010. A comparative study of incentive motivation, achievement motivation and anxiety level between national and international hockey players. Brit. J. Sports Med., 44, 58-58. DOI: 10.1136/bjsm.2010.078725.195

Franken, R.E. 2007. Human Motivation. 6th Edn., Thomson/Wadsworth, Australia, ISBN:

Jones, M. V., 2003. Controlling emotions in sport. Sport Psychol., 17: 471-486. http://tonypickering.com/documents/Jones_2003.pdf

Kamlesh, M.L., 2004. Athletic Personality: A Psychological Probe. Khel Sahitya Kendra K.S.K. Publishers and Distributors, New Delhi, ISBN: 8175242450, pp: 284.
Lawther, J.D., 1972. Sport Psychology. $1^{\text {st }}$ Edn., Prentice-Hall, Englewood Cliffs, NJ., ISBN: 013835488X, pp: 193.

Miller, K.E. and J.H. Hoffman, 2009. Mental wellbeing and sport-related identities in college students. Soc. Sport J., 26: 335-356. PMID: 20661467 PMCid:2908331

Moreno-Murcia, J.A., Sicilia, A., Eduardo Cervelló, E., Elisa Huéscar, E. and D.C. Dumitru, 2011. The relationship between goal orientations, motivational climate and self-reported discipline in physical education. J. Sports Sci. Med., 10: 119-129. http://www.doaj.org/doaj?func=abstract\&id=699485

Ormrod, J.E., 2010. Essentials of Educational Psychology. 3rd Ed. Prentice Hall PTR., Boston, ISBN: 0131367277, pp: 410.

Pangma, R., S. Tayraukham, and P. Nuangchalerm, 2009. Causal Factors Influencing Adversity Quotient of Twelfth Grade and Third-Year Vocational Students. J. Soc. Sci., 5: 466-470. DOI: 10.3844/JSSP.2009.466.470

Parveen, N. and Y. Iqbal, 2007. Gender differences in emotional intelligence among professional athletes of Hyderabad city. University of Sindh. http://www.usindh.edu.pk/shield/shield2007.pdf\#page $=31$

Pensgaard, A. M. and J.L. Duda, 2003. Sydney 2000: the interplay between emotions, coping and the performance of Olympic-level athletes. Sport Psychologist. 17: 253-267. http://www.cabdirect.org/abstracts/20033165695.ht $\mathrm{ml}$;jsessionid=6ECFDDCC19CFD2B05F40119F21 C5D9D6

Quested, E. and J.L. Duda, 2009. Perceptions of the motivational climate, need satisfaction, and indices of well- and ill-being among hip hop dancers. J. Dance Med. Sci., 13, 10-19. PMID: 19416610

Reinboth, M. and J.L. Duda, 2006. Perceived motivational climate, need satisfaction and indices of well-being in team sports: A longitudinal perspective. Psychol. Sport Exerc., 7: 269-286. DOI: 10.1016/J.PSYCHSPORT.2005.06.002

Schilling, T.A. and C.T. Hayashi, 2001. Achievement motivation among high school basketball and crosscountry athletes: a personal investment perspective. J. Applied Sport Psychol., 13: 103-128. DOI: 10.1080/10413200109339006

Vallerand, R.J. and C.M. Blanchard, 2000. The study of emotion in sport and exercise: Historical, definitional and conceptual perspectives. In U.L.V. Khanin, (Ed.), Emotions in Sport, Human Kinetics, Champaign, ISBN: 0880118792, pp: 3-38.

Weinberg, R., R.S. Weinberg and D. Gould, 2010. Foundations of Exercise Psychology. 5th Edn., Human Kinetics, Champaign, ISBN: 0736083235, pp: 640 . 